\title{
INFLUENCE OF MESOPHASE ACTIVATION CONDITIONS ON THE SPECIFIC CAPACITANCE OF THE RESULTING CARBONS
}

\author{
E. Mora, V. Ruiz, R. Santamaría, C. Blanco*, M. Granda, R. Menéndez, \\ J.M. Juarez-Galán", F. Rodríguez-Reinoso ${ }^{\#}$ \\ Instituto Nacional del Carbón, CSIC, Apdo. 73, 33080-Oviedo (Spain)

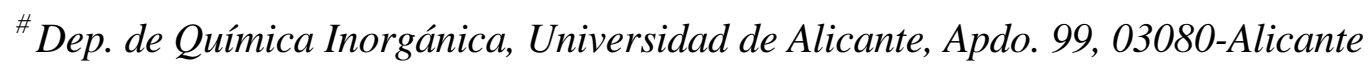
(Spain)

\begin{abstract}
Mesophase pitch AR24 was directly activated with $\mathrm{KOH}$ using different proportions of the activating agent and activation temperatures, to study the effect on the textural characteristics of the resultant activated carbons and how these characteristics influence their behaviour as electrodes in supercapacitors. The textural properties of the activated carbons were studied by gas adsorption and immersion calorimetry. The results indicate that all the carbons produced were mainly microporous, with pore size around $1 \mathrm{~nm}$. The behaviour of these carbons as electrodes in supercapacitors was studied from galvanostatic charge-discharge cycles. The specific capacitance values obtained were very high, reaching $400 \mathrm{~F} / \mathrm{g}$ and $200 \mathrm{~F} / \mathrm{g}$ at low and high current densities respectively, for the sample activated with $(5: 1) \mathrm{KOH}$ to mesophase ratio. Nevertheless, the reasons for this high capacitance values cannot be explained only on the basis of the textural characteristics of the activated carbons, as the results indicated that other factors might be also playing a significant role in their electrochemical behaviour.
\end{abstract}

Keywords- Supercapacitors, Activated carbons, Mesophase pitch

\footnotetext{
*Corresponding author: FAX: +34 9852976 62; e-mail: clara@incar.csic.es
} 


\section{Introduction}

Supercapacitors have been presented in the last years as an important alternative or complement to other energy storage or generation devices such as secondary batteries and fuel cells [1]. Carbon materials have been shown as the most attractive electrode materials for these supercapacitors, as a consequence of their relatively low cost, high surface area and availability [2]. Although non-graphitizable carbons are usually preferred to produce high surface area materials, the use of graphitizable carbons could bring some advantages for this application, such as a lower electrical resistivity and a higher density.

Despite intensive research in this field has significantly increased along the last years, there is still a strong need for understanding the role played by the porosity and the interactions between the porous carbon and the liquid electrolyte. The situation is complex because of the large variety of carbon precursors. The classical activated carbons are based on lignocellulosic or coal-derived materials [3], which are characterised by a low crystalline order, while other high surface carbon materials can be derived from such diverse materials as nanotubes [4] or graphitic carbon fibres [5], which present a much higher crystalline order. In addition to the different nature of the precursors, the activation procedures used to develop surface area in each case may be different (i.e. physical or chemical activation) [3-7], which can still generate further differences in the characteristics of the surface. Therefore, the textural study of the carbons (including the surface area and pore volume or pore size distribution) might be 
necessary but not sufficient to fully understand the behaviour of the carbon electrodes in the supercapacitors. Detailed analysis of the carbon chemistry is needed to achieve a better understanding of the interaction of the carbon and the electrolyte during the double layer formation.

In this paper, mesophase pitch AR24 was chemically activated with $\mathrm{KOH}$ under different conditions to produce porous carbons that were then used as electrodes in supercapacitors. The influence that the activation conditions have on the type of porosity developed in the mesophase and the relationships between this porosity and the specific capacitance of the materials are investigated.

\section{Experimental}

\subsection{Preparation of activated carbons.}

Naphthalene-derived mesophase pitch produced by Mitsubishi Gas Chemicals, AR24, was chemically activated with $\mathrm{KOH}$ under different conditions. As-received mesophase pitch was mixed with the activating agent (1:1 to $5: 1 \mathrm{KOH}$ to carbon mass ratio) by grinding in a mortar and then carbonised at temperatures between 600 and $800{ }^{\circ} \mathrm{C}$ for one hour, under a nitrogen flow of $62 \mathrm{~mL} \mathrm{~min}^{-1}$. The heating rate used was $2.5^{\circ} \mathrm{C} / \mathrm{min}$. After completing the treatment the sample was allowed to cool freely to room temperature. The resultant material was neutralized with $1 \mathrm{M} \mathrm{HCl}$ and then washed with distilled water until $\mathrm{pH}=7$. Finally, the carbon was dried at $110^{\circ} \mathrm{C}$ in a vacuum oven for $24 \mathrm{~h}$. A series of mesophase-derived activated carbons was obtained using a fixed $\mathrm{KOH}$ to carbon ratio $(3: 1)$ and activation temperatures of 600,700 and $800^{\circ} \mathrm{C}$ for $1 \mathrm{~h}$. A second series was obtained at $700{ }^{\circ} \mathrm{C}$ for $1 \mathrm{~h}$ but using different proportions of $\mathrm{KOH}$ 
and carbon (1:1, 3:1 and 5:1). The resultant activated carbons were labelled AR.3.6, AR.3.7, AR.3.8, AR.1.7 and AR.5.7, respectively, where the first number indicates the ratio of $\mathrm{KOH}$ used and the second one refers to the activation temperature $\left(6\right.$ for $600{ }^{\circ} \mathrm{C}$, etc.). Table 1 summarises the activation conditions used to activate the mesophase pitch.

\subsection{Characterisation of activated carbons.}

The resultant activated carbons were characterized by elemental analysis, with direct determination of oxygen, using a LECO-TF-900 furnace coupled to a LECO-CHNS932 microanalyser.

Physical adsorption of gases $\left(\mathrm{N}_{2}\right.$ at $77 \mathrm{~K}$ and $\mathrm{CO}_{2}$ at $273 \mathrm{~K}$ ) was carried out in order to characterise the porous structure of the activated carbons. Apparent surface areas were determined by BET equation from the $\mathrm{N}_{2}$ adsorption isotherm. The total micropore volume was calculated from the application of the Dubinin-Radushkevich (DR) equation to the $\mathrm{N}_{2}$ adsorption at $77 \mathrm{~K}$. The volume of narrow micropores (pore size smaller than $0.7 \mathrm{~nm}$ ) was assessed from $\mathrm{CO}_{2}$ adsorption at $273 \mathrm{~K}$ [8]. The total pore volume was obtained from the $\mathrm{N}_{2}$ adsorption at $\mathrm{P} / \mathrm{P}_{0}=0.99$. The volume of mesopores was calculated by substracting the total micropore volume from the total pore volume.

The microporosity of the activated carbons was further characterised by measuring the enthalpy of immersion of the samples into liquids of different critical dimensions [9]. Measurements were carried out at $20^{\circ} \mathrm{C}$ using dichloromethane $\left(\mathrm{CH}_{2} \mathrm{Cl}_{2}, \mathrm{~L}=0.33 \mathrm{~nm}\right)$, benzence $\left(\mathrm{C}_{6} \mathrm{H}_{6}, \mathrm{~L}=0.41 \mathrm{~nm}\right)$, carbon tetrachoride $\left(\mathrm{CCl}_{4}, \mathrm{~L}=0.63 \mathrm{~nm}\right)$, tetraisopropyl-otitanate (TIPOT, L=1.05 nm) and tetrabutyl-o-titanate (TBOT, $\mathrm{L}=1.3 \mathrm{~nm}$ ). Additionally, 
immersion calorimetry into water was used as an indication of the hydrophilic/hydrophobic character of the carbon surface [10].

\subsection{Electrochemical characterisation of activated carbons.}

The electrochemical performance of the activated carbons in supercapacitors was studied from galvanostatic charge-discharge cycles of a two electrode Swagelok type cell using an aqueous solution of sulphuric acid (2 M) as electrolyte. Coin type carbon electrodes (13 $\mathrm{mm}$ in diameter and about $500 \mu \mathrm{m}$ in thickness) were prepared by mixing 90 wt. $\%$ of the activated carbon with 10 wt. \% of PVDF as binder. The capacitor was constructed using two of these electrodes, separated by a disc of glassy paper. The specific capacitance was calculated from the linear region $(\sim 0.2-0.6 \mathrm{~V})$ of the discharge branch, taking into account the mass of activated carbon used in the lightest electrode. Galvanostatic charge-discharge characteristics were measured in the range of $0-1 \mathrm{~V}$ at various current intensities (1-100 mA).

\section{Results and Discussion}

\subsection{Characteristics of activated carbons}

The weight loss values obtained for the chemical activation of the mesophase pitch under the conditions studied are summarised in Table 1 . The increase in the activation temperature caused the weight loss to increase slightly, from 22 to $28 \%$ for samples AR.3.6 and AR.3.8, respectively. The increase in the $\mathrm{KOH}$ to mesophase ratio also increased the weight loss of the samples, but in this case the changes are more significant (16 wt. \% for AR.1.7 and 45 wt. \% for AR.5.7). Activation also caused a significant amount of oxygen to be incorporated into the samples (Table 1), especially 
in the case of samples AR.3.6 (13.96 wt. \%) and AR.3.7 (10.31 wt. \%). Despite the low activation degree of sample AR.1.7, the oxygen content of this sample is significantly high (8.28 wt. \%). As could be expected, the oxygen content decreases significantly when activation is carried out at $800^{\circ} \mathrm{C}$, as a result of the release of oxygenated compounds such as $\mathrm{CO}$ and $\mathrm{CO}_{2}$.

Figure 1 shows the nitrogen adsorption isotherms corresponding to the samples activated at different temperatures (Figure 1a) and to those obtained using different amounts of $\mathrm{KOH}$ (Figure 1b). All samples show type I isotherm profiles, characteristic of microporous carbons. The increase in the activation temperature and the amount of activating agent used enhance the uptake of nitrogen at $77 \mathrm{~K}$. This is reflected in the total pore volume developed in the samples (Table 2), which increased from 0.76 to $0.99 \mathrm{~cm}^{3} / \mathrm{g}$ in the activation temperature series and more significantly in the series obtained with different amounts of $\mathrm{KOH}$, increasing from 0.42 to $1.05 \mathrm{~cm}^{3} / \mathrm{g}$ for samples AR.1.7 and AR.5.7, respectively. The shape of the isotherms does not change significantly in the temperature series, the knee being only slightly wider for sample AR.3.8 (Figure 1a). On the contrary, the increase in the amount of $\mathrm{KOH}$ caused the knee of the isotherm to widen to a great extent (Figure 1b), this indicating that the micropore size distribution is widening from AR1.7 to AR5.7. These results are in agreement with those obtained by Kim et al. [5], when studying the activation of carbon fibres with different amounts of $\mathrm{KOH}$.

The total micropore volume (up to $2 \mathrm{~nm}$ ) increases with increasing activation temperature ( 0.70 to 0.88 for AR.3.6 and AR.3.8, respectively). On the other hand, the 
behaviour is different when the amount of $\mathrm{KOH}$ is increased. Increasing the $\mathrm{KOH}$ to mesophase ratio from 1:1 to $3: 1$ caused the micropore volume to increase significantly (from 0.39 to $0.83 \mathrm{~cm}^{3} / \mathrm{g}$ ). However, when the ratio of $\mathrm{KOH}$ is $5: 1$, the micropore volume decreased despite the total pore volume in this sample increased. This indicates that not only micropores but also larger pores have been developed in this sample, in agreement with the shape of the isotherm discussed before. In fact, the contribution of mesopores in this sample is $0.25 \mathrm{~cm}^{3} / \mathrm{g}$ (Table 2). A small contribution of mesopores is also present in sample AR.3.8 $\left(0.11 \mathrm{~cm}^{3} / \mathrm{g}\right)$, but it is negligible for the other three samples. The $\mathrm{CO}_{2}$ adsorption isotherms confirmed the results obtained by the $\mathrm{N}_{2}$ adsorption, indicating that there are no diffusion problems in the samples [11]. The micropore volumes calculated from the $\mathrm{CO}_{2}$ adsorption isotherms are very similar to the values obtained from the $\mathrm{N}_{2}$ adsorption isotherms, the differences between these values being almost negligible (Table 2). AR.1.7 is the only sample where the values obtained from the $\mathrm{CO}_{2}$ isotherm are higher than those obtained from the $\mathrm{N}_{2}$ one, indicating the existence of narrow microporosity for which the access of $\mathrm{N}_{2}$ at $77 \mathrm{~K}$ is kinetically restricted. On the other hand, AR.5.7 is the only sample with a significant positive value $\left(\mathrm{VN}_{2}-\mathrm{VCO}_{2}=0.09 \mathrm{~cm}^{3} / \mathrm{g}\right)$ confirming the widening of the pores with the highest $\mathrm{KOH}$ to carbon ratio studied.

The apparent BET surface areas of the activated carbons (Table 2) increased with increasing activation temperature (from 1776 to $2307 \mathrm{~m}^{2} / \mathrm{g}$ ) and also with increasing amount of $\mathrm{KOH}$ used (from 963 to $2173 \mathrm{~m}^{2} / \mathrm{g}$ ). However, it is worth noting that although AR.5.7 is the sample with the larger volume of pores, the highest surface area 
corresponds to sample AR.3.8, due to the widening of the micropores observed in AR.5.7, as discussed before.

Immersion calorimetry into liquids of different size provides further information on the microporosity present in the samples [9]. The immersion enthalpies obtained for the activated carbons studied are summarised in Table 3 . In general, the immersion enthalpies obtained are very high, even higher than for activated carbons of similar micropore volumes [12], as expected in view of the high volume of narrow micropores. The data shown in Table 3 reveal that most carbons have micropore sizes around 1.0 $\mathrm{nm}$, as high immersion enthalpies were still obtained for TIPOT (nominal molecular diameter $1.03 \mathrm{~nm}$ ), while a dramatic decrease is observed for the largest molecular probe used (TBOT diameter is $1.3 \mathrm{~nm}$ ). A more detailed observation of the data shows significant differences between the samples. AR.1.7 shows the lowest heats of immersion in all the different liquids due to its lowest activation degree, as demonstrated above with the data derived from the isotherms. The presence of pores larger than $0.7 \mathrm{~nm}$ is limited in this sample, as a significant decreased of the heat of immersion is already noticeable for the $\mathrm{CCl}_{4}(0.63 \mathrm{~nm})$. This is in good agreement with the data obtained from the adsorption isotherms, where this sample presented a volume of $\mathrm{CO}_{2}$ slightly higher than the volume of $\mathrm{N}_{2}$. The sample less activated in the temperature series, AR.3.6, also shows a clear decrease in the heats of immersion as the size of the molecular probes increase, which indicates the presence of pores of smaller size. This was not clearly observed from the adsorption data. Finally, AR.5.7 has the highest value of immersion enthalpy in TBOT, confirming the widening of the pores as the $\mathrm{KOH} /$ carbon ratio is increased. 
The enthalpies of immersion into water were used to estimate the number of hydrophilic groups [10] present in the activated carbons (Table 3). As could be expected, sample AR.3.6, which has the highest oxygen content, also has the highest content of hydrophilic groups, while the sample heat treated to $800^{\circ} \mathrm{C}$ is the less hydrophilic, in agreement with its lowest oxygen content. However, it is worth noting that sample AR.1.7 has a relatively low content in hydrophilic groups, despite the high oxygen content $(8.28$ wt. \%). This suggests that the type of oxygen functionalities present in this activated carbon could be different to those present in the rest of the samples studied, with a higher degree of activation.

\subsection{Electrochemical performance of activated carbons}

The capacitance of the activated carbons prepared was studied from the galvanostatic charge-discharge cycles of a two-electrode cell at different current densities. An example of the charge-discharge profiles obtained for the different samples at $5 \mathrm{~mA}$ is shown in Figure 2. All samples except AR.3.6 show triangular chronopotentiograms, indicating a typical behaviour of capacitive electrodes. In general, the initial voltage rise/drop observed in the charge/discharge profiles, which correspond to the ESR, is relatively small except for sample AR.3.6. Additionally, the voltage drop corresponding to this sample is followed by a non-linear decrease of the voltage with time. This made it difficult to calculate the capacitance values for sample AR.3.6, and the values plotted in Figure 3 are only indicative. As the ESR increases with increasing current density, it was not possible to calculate capacitance values at current densities higher than 7.4 
$\mathrm{mA} / \mathrm{cm}^{2}$ for this sample. The behaviour observed could be related to the extremely high oxygen content of this sample (nearly $14 \mathrm{wt} . \%$ ) or to the lower temperature at which this activated carbon was obtained, which could have made the resistivity to be higher. Another reason that could explain this anomalous behaviour of AR.3.6, which is usually described in the literature, could be the difficulties of the electrolyte diffusion in the narrow microporosity. In this case this argument has to be refuted as it has been demonstrated the AR.1.7 has pores of smaller size while its electrochemical behaviour does present neither a significant ESR nor a deviation from linearity.

The variation of the specific capacitance of the activated carbons with current density is shown in Figure 3. It is worth noting the high values of specific capacitance obtained for the different samples, reaching $400 \mathrm{~F} / \mathrm{g}$ at low current densities in the case of sample AR.5.7. The behaviour of samples AR.3.7 and AR.3.8 is very similar both at low and high current densities. The specific capacitance in these samples varies from around 320 $\mathrm{F} / \mathrm{g}\left(\right.$ at $0.75 \mathrm{~mA} / \mathrm{cm}^{2}$ ) to around $150 \mathrm{~F} / \mathrm{g}\left(\right.$ at $75 \mathrm{~mA} / \mathrm{cm}^{2}$ ). The sample activated with the lowest amount of $\mathrm{KOH}$ (AR.1.7) has the lowest specific capacitance (200 F/g at low current densities), which is due to the significantly lower surface area developed in this sample. The higher values of capacitance obtained for sample AR.5.7 (406 and $210 \mathrm{~F} / \mathrm{g}$ for low and high current densities, respectively) could be related both to the high surface area developed and also to the larger pores of this sample (it contains larger micropores and a higher proportion of mesopores than the rest of the samples).

Although the explanations based on the textural characteristics of the samples might be satisfactory in the series of samples obtained varying the $\mathrm{KOH}$ to carbon ratio, a more 
complex situation arises in the temperature series. The electrochemical behaviour of these samples is very similar but significant differences were found in their textural characteristics (Table 2), both in surface area and pore volumes. These samples also showed important differences in their chemical composition, like oxygen content (Table 1) or hydrophilic character (Table 3). Although these factors might be important in the formation of the double layer, there might be other properties of the carbon or carbonelectrolyte interactions that could be contributing to the high specific capacitance observed. The need for new research focusing on properties of the carbon materials other than the textural ones can be demonstrated with the recent work of Inagaki et al. [13], where very high specific capacitances $(450 \mathrm{~F} / \mathrm{g})$ where obtained in materials of relatively low surface area $\left(320 \mathrm{~m}^{2} / \mathrm{g}\right)$.

The high values of specific capacitance obtained in this study are close to the highest values ever found for carbon materials, although the textural properties of our carbons cannot be considered exceptional. Other authors working with activated carbons based on anisotropic precursors have found similar results [14-15], which seems to indicate that activated carbons obtained from these precursors have some advantages for the storage of energy in the double layer when compared to other carbons. Furthermore, the results presented here indicate that it is possible to obtain high capacitance values from samples that are mainly microporous, with pore size around $1 \mathrm{~nm}$. It is worth noting that, although a significant decrease of the specific capacitance with increasing current density was observed (Figure 3), the values obtained at high current densities are still significantly high $(\sim 150-200 \mathrm{~F} / \mathrm{g})$. The causes of this dependence of the capacitance with the current density are not clear. This variation cannot be exclusively attributed to 
the presence of microporosity, as suggested by many authors, as the loss of capacitance is similar for all the samples independently of the textural characteristics. This can be clearly deduced from the behaviour of samples AR.1.7 and AR.5.7 (Figure 3). The decrease in specific capacitance is about $50 \%$ in both cases, despite the pores in sample AR.5.7 are significantly larger than in sample AR.1.7, as discussed above.

\section{Conclusions}

Activated carbons with high surface areas have been developed from the direct activation of mesophase pitch with $\mathrm{KOH}$ under different conditions. The increase in the activation temperature caused the surface area and micropore volume to increase. Meanwhile, the activation with the highest $\mathrm{KOH}$ to mesophase ratio (5:1) also caused the widening of the pores with no substantial increase in the surface area.

Immersion calorimetry into liquids of different molecular size confirmed the results obtained by gas adsorption. Additionally, the number of hydrophilic sites in the samples, estimated by immersion into water, was higher for those samples with higher oxygen content, except for the least activated sample (AR.1.7). The combination of both techniques shows that the size of the pores are around $1.0 \mathrm{~nm}$ for most of the activated carbons, with few pores over $1.3 \mathrm{~nm}$ (except for sample AR.3.5) or under $0.7 \mathrm{~nm}$.

The activated carbons studied showed very high values of specific capacitance, reaching in some cases $400 \mathrm{~F} / \mathrm{g}$ for low current densities and values around 150-200 F/g for high current densities, values which are relatively high in comparison with other described in the literature. In the series of carbons obtained with increasing the $\mathrm{KOH}$ to mesophase 
ratio, the capacitance increased with increasing the surface area and pore volume of the samples. However, in the temperature series, the capacitance was rather similar, despite the different textural characteristics observed. This, together with the fact that the dependance of the capacitance with current density was similar for all the samples, suggest that there are other factors in addition to surface area and pore size that might be contributing to the formation of the double layer and the amount of energy stored in it. A significant effort is needed for the elucidation of the mechanism of the double layer formation.

Acknowledgements.- The authors would like to thank Spanish Education Ministry for financial support (Project MAT2003-03480-C02). V. Ruiz acknowledges a predoctoral research grant from FICYT.

\section{References}

[1] R. Kötz, M. Carlen. Principles and applications of electrochemical capacitors. Electrochimica Acta, 45 (2000) 2483-2498.

[2] E. Frackowiak, F. Béguin. Carbon materials for the electrochemical storage of energy in capacitors. Carbon, 39 (2001) 937-950.

[3] D. Lozano-Castelló, D. Cazorla-Amorós, A. Linares-Solano, S. Shiraishi, H. Kurihara, A. Oya. Influence of pore structure and surface chemistry on electric double layer capacitance in non-aqueous electrolyte. Carbon, 41 (2003) 1765-1775.

[4] E. Frackowiak , K. Jurewicz, S. Delpeux, F. Beguin. Nanotubular materials for supercapacitors. Journal of Power Sources, 97-98 (2001) 822-825. 
[5] Y.J. Kim, Y. Horie, Y. Matsuzawa, S. Ozaki, M. Endo, M. Dresselhaus. Structural features necessary to obtain a high specific capacitance in electric double layer capacitors. Carbon, 42 (2004) 2423-2432.

[6] K. Babel, K. Jurewicz. Electrical capacitance of fibrous carbon composites in supercapacitors. Fuel Processing technology, 77-78 (2002) 181-189.

[7] S. Mitani, S.I. Lee, S.H. Yoon, Y. Korai, I. Mochida. Activation of raw pitch coke with alkali hydroxide to prepare high preformance carbon for electric double layer capacitor. Journal of Power Sources, 133 (2004) 298-301.

[8] F. Rodríguez-Reinoso, J. Garrido, J.M. Martín-Martínez, M. Molina-Sabio, Torregrosa R. The combined use of different approaches in the characterization of microporous carbons. Carbon, 27 (1989) 23-32.

[9] F. Stoeckli, T.A. Centeno. On the characterisation of microporous carbons by immersion calorimetry alone. Carbon, 8 (1997) 1097-1100.

[10]F. Stoeckli. Water adsorption in activated carbons of various degrees of oxidation described by the Dubinin equation. Carbon, 40 (2002) 955-971.

[11] F. Rodríguez-Reinoso, A. Linares-Solano. Microporous structure of activated carbons as revealed by adsorption methods, in: Thrower PA, editor, Chemistry and physics of carbon, Marcel Dekker New York, vol. 21, 1988, pp. 1-146.

[12] F. Stoeckli, T.A. Centeno, J.B. Donnet, N. Pusset. Characterization of industrial activated carbons by adsorption and immersion techniques and by STM. Fuel, 74 (1995) 1582-1588.

[13] Y. Soneda, M. Toyoda, J. Yamashita, M. Kodama, H. Hatori, M. Inagaki. Extended abstracts Carbon 2004, Providence (Rhode Island, USA); CD-ROM Paper E026. 
[14] K. Kierzek, E. Frackowiak, G. Lota, G. Gryglewicz, J. Machnikowski. Electrochemical capacitors based on highly porous carbons prepared by $\mathrm{KOH}$ activation. Electrochimica Acta, 49 (2004) 515-523.

[15] H. Shi. Activated carbons and double layer capacitance. Electrochimica Acta 41 (1996) 1633-1639. 


\section{Table Captions}

Table 1.- Activation conditions and characteristics of activated carbons.

Table 2.- Textural characteristics of activated carbons.

Table 3.- Immersion enthalpies into different liquids. 
Table 1.- Activation conditions and characteristics of activated carbons.

\begin{tabular}{cccccc}
\hline Sample & $\begin{array}{c}\text { Temperature } \\
\left({ }^{\circ} \mathrm{C}\right)\end{array}$ & $\begin{array}{c}\text { KOH:mesofase } \\
\text { ratio }\end{array}$ & $\begin{array}{c}\text { Residence } \\
\text { time (h) }\end{array}$ & $\begin{array}{c}\text { Weight loss } \\
(\text { wt. \%) }\end{array}$ & O (wt. \%) \\
\hline AR.3.6 & 600 & $3: 1$ & 1 & 22 & 13.94 \\
AR.3.7 & 700 & $3: 1$ & 1 & 24 & 10.31 \\
AR.3.8 & 800 & $3: 1$ & 1 & 28 & 3.73 \\
AR.1.7 & 700 & $1: 1$ & 1 & 16 & 8.28 \\
AR.5.7 & 700 & $5: 1$ & 1 & 45 & 4.88 \\
\hline
\end{tabular}


Table 2. Textural characteristics of activated carbons.

\begin{tabular}{lcccccc}
\hline Sample & $\begin{array}{c}\mathrm{BET} \\
\left(\mathrm{m}^{2} / \mathrm{g}\right)\end{array}$ & $\begin{array}{c}\mathrm{VT} \\
\left(\mathrm{cm}^{3} / \mathrm{g}\right)\end{array}$ & $\begin{array}{c}\mathrm{VN}_{2} \\
\left(\mathrm{~cm}^{3} / \mathrm{g}\right)\end{array}$ & $\begin{array}{c}\mathrm{VCO}_{2} \\
\left(\mathrm{~cm}^{3} / \mathrm{g}\right)\end{array}$ & $\begin{array}{c}\mathrm{VN}_{2}-\mathrm{VCO}_{2} \\
\left(\mathrm{~cm}^{3} / \mathrm{g}\right)\end{array}$ & $\begin{array}{c}\mathrm{Vmeso}^{3} \\
\left(\mathrm{~cm}^{3} / \mathrm{g}\right)\end{array}$ \\
\hline AR.3.6 & 1776 & 0.76 & 0.70 & 0.68 & 0.02 & 0.06 \\
AR.3.7 & 2044 & 0.84 & 0.83 & 0.80 & 0.03 & 0.01 \\
AR.3.8 & 2307 & 0.99 & 0.88 & 0.84 & 0.04 & 0.11 \\
AR.1.7 & 963 & 0.42 & 0.39 & 0.43 & -0.04 & 0.03 \\
AR.5.7 & 2173 & 1.05 & 0.80 & 0.71 & 0.09 & 0.25 \\
\hline
\end{tabular}

BET, BET surface area

VT, total pore volume

$\mathrm{VN}_{2}$, micropore volume determined from the $\mathrm{N}_{2}$ isotherms.

$\mathrm{VCO}_{2}$, micropore volume determined from the $\mathrm{CO}_{2}$ isotherms.

Vmeso, mesopore volume 
Table 3. Immersion enthalpies into different liquids.

\begin{tabular}{cccccccc}
\hline Sample & $-\Delta_{\mathrm{i}} \mathrm{H}_{\mathrm{CH} 2 \mathrm{Cl} 2}$ & $-\Delta_{\mathrm{i}} \mathrm{H}_{\mathrm{C} 6 \mathrm{H} 6}$ & $-\Delta_{\mathrm{i}} \mathrm{H}_{\mathrm{CCl} 4}$ & $-\Delta_{\mathrm{i}} \mathrm{H}_{\mathrm{TIPOT}}$ & $-\Delta_{\mathrm{i}} \mathrm{H}_{\mathrm{TBOT}}$ & $-\Delta_{\mathrm{i}} \mathrm{H}_{\mathrm{H} 2 \mathrm{O}}$ & $n^{\mathrm{o}} \mathrm{Hyd}$ \\
\hline AR.3.6 & 237 & 232 & 198 & 171 & 31 & 100 & 5.1 \\
AR.3.7 & 252 & 237 & 255 & 285 & 21 & 83 & 3.3 \\
AR.3.8 & 261 & 261 & 251 & 260 & 31 & 69 & 1.4 \\
AR.1.7 & 164 & 150 & 90 & 118 & 15 & 50 & 1.8 \\
AR.5.7 & 241 & 255 & 239 & 267 & 85 & 79 & 2.5 \\
\hline
\end{tabular}

$-\Delta_{\mathrm{i}} \mathrm{H}$, immersion enthalpy, $\mathrm{J} / \mathrm{g}$

$\mathrm{n}^{\circ} \mathrm{Hyd}$, number of hydrophilic sites, meq/g 


\section{Figure Captions}

Figure 1.- $\mathrm{N}_{2}$ adsorption isotherms of activated carbons obtained: a) at different temperatures; b) with different $\mathrm{KOH}$ to mesophase ratio.

Figure 2.- Charge-discharge profiles at $5 \mathrm{~mA}$ of supercapacitors prepared with activated carbons obtained: a) at different temperatures; b) with different $\mathrm{KOH}$ to mesophase ratio. Electrode mass: $50 \mathrm{mg}$.

Figure 3.- Variation of the specific capacitance with the current density of activated carbons obtained: a) at different temperatures; b) with different $\mathrm{KOH}$ to mesophase ratio. Electrode mass: $50 \mathrm{mg}$. 
a)

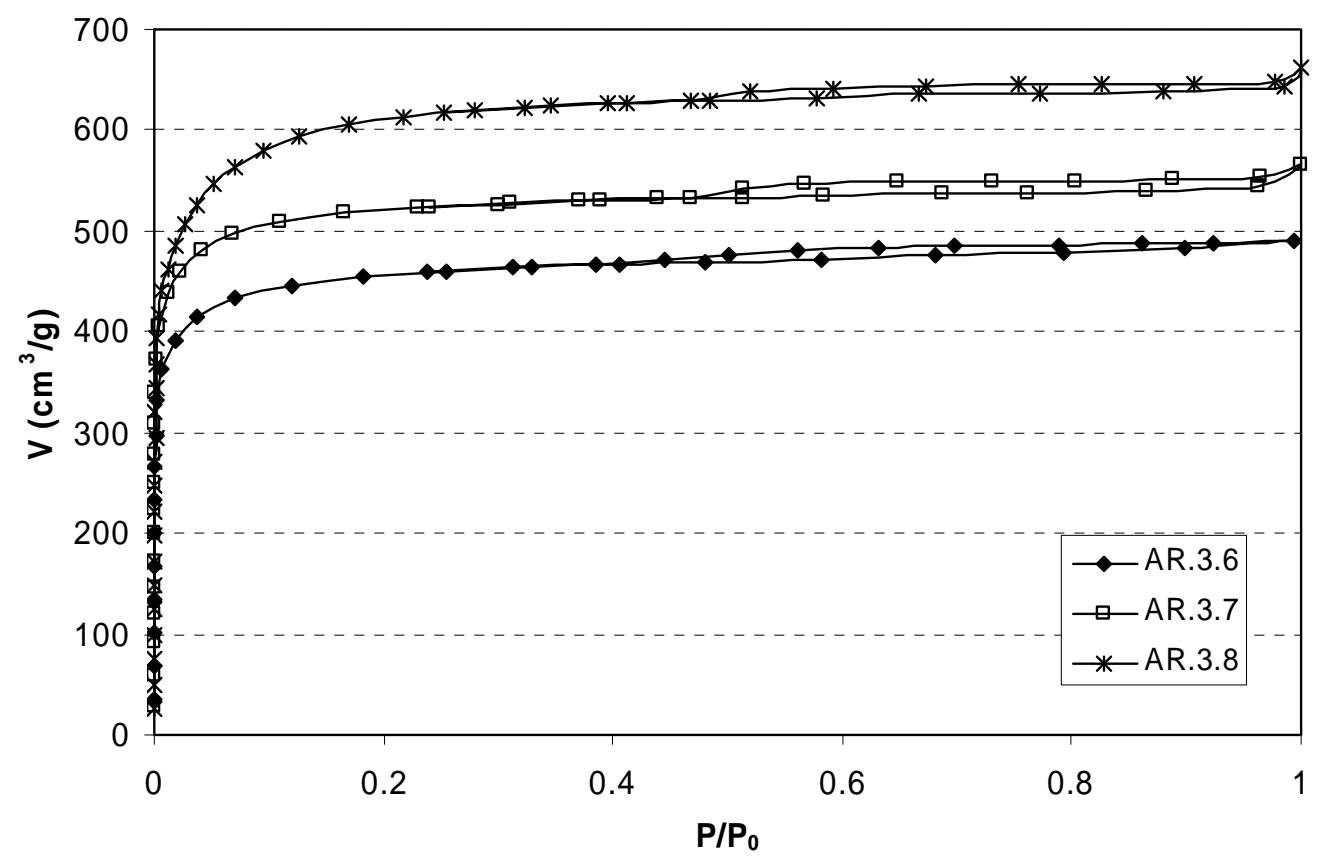

b)

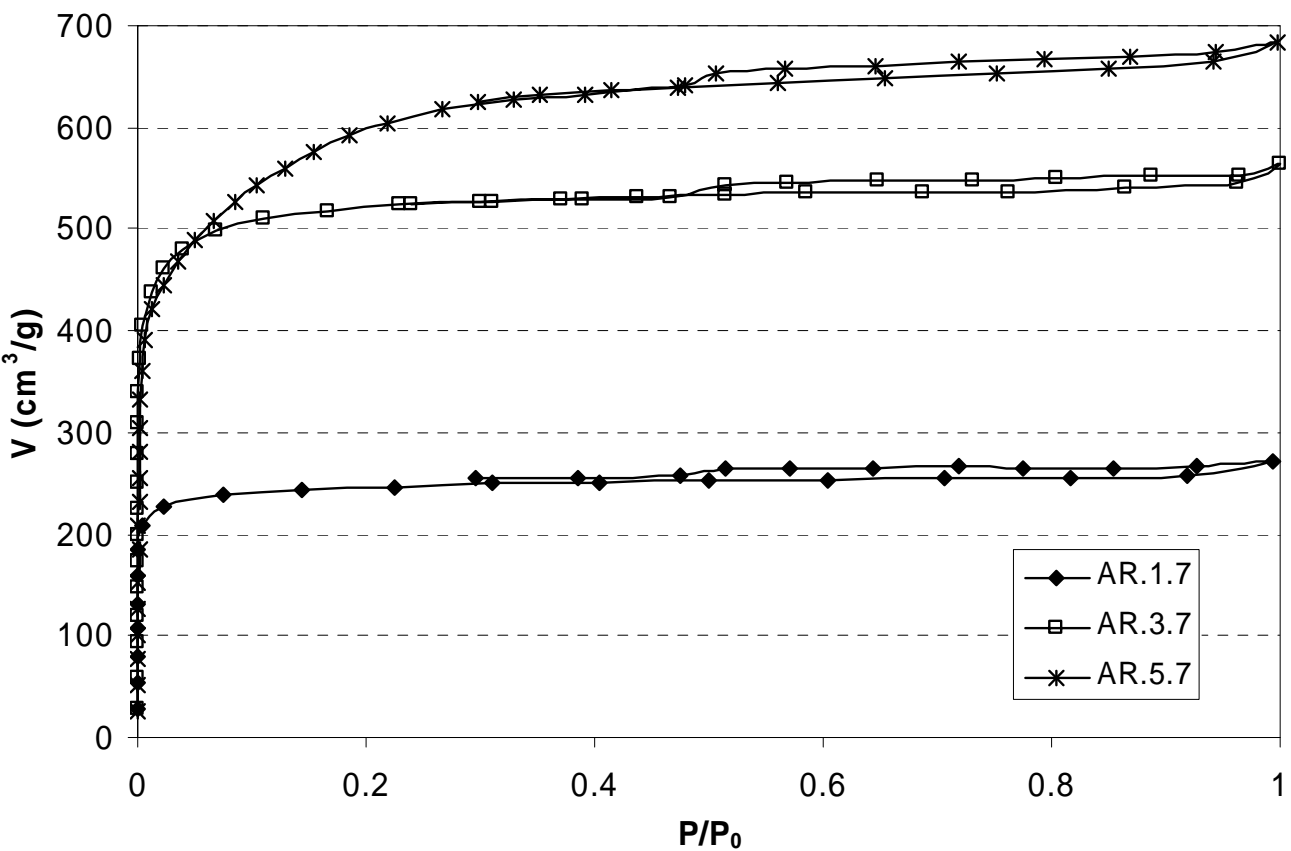

Figure 
a)

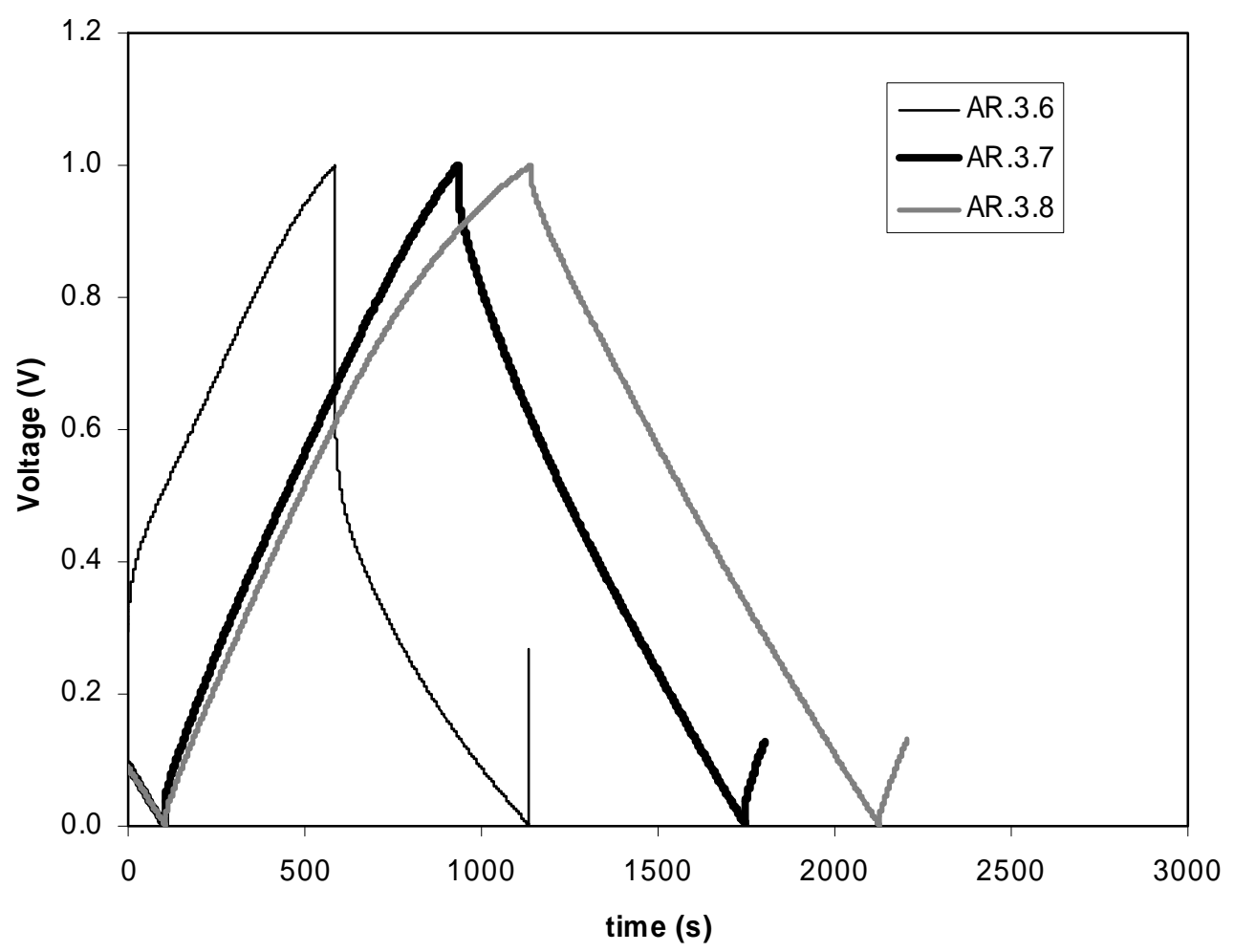

b)

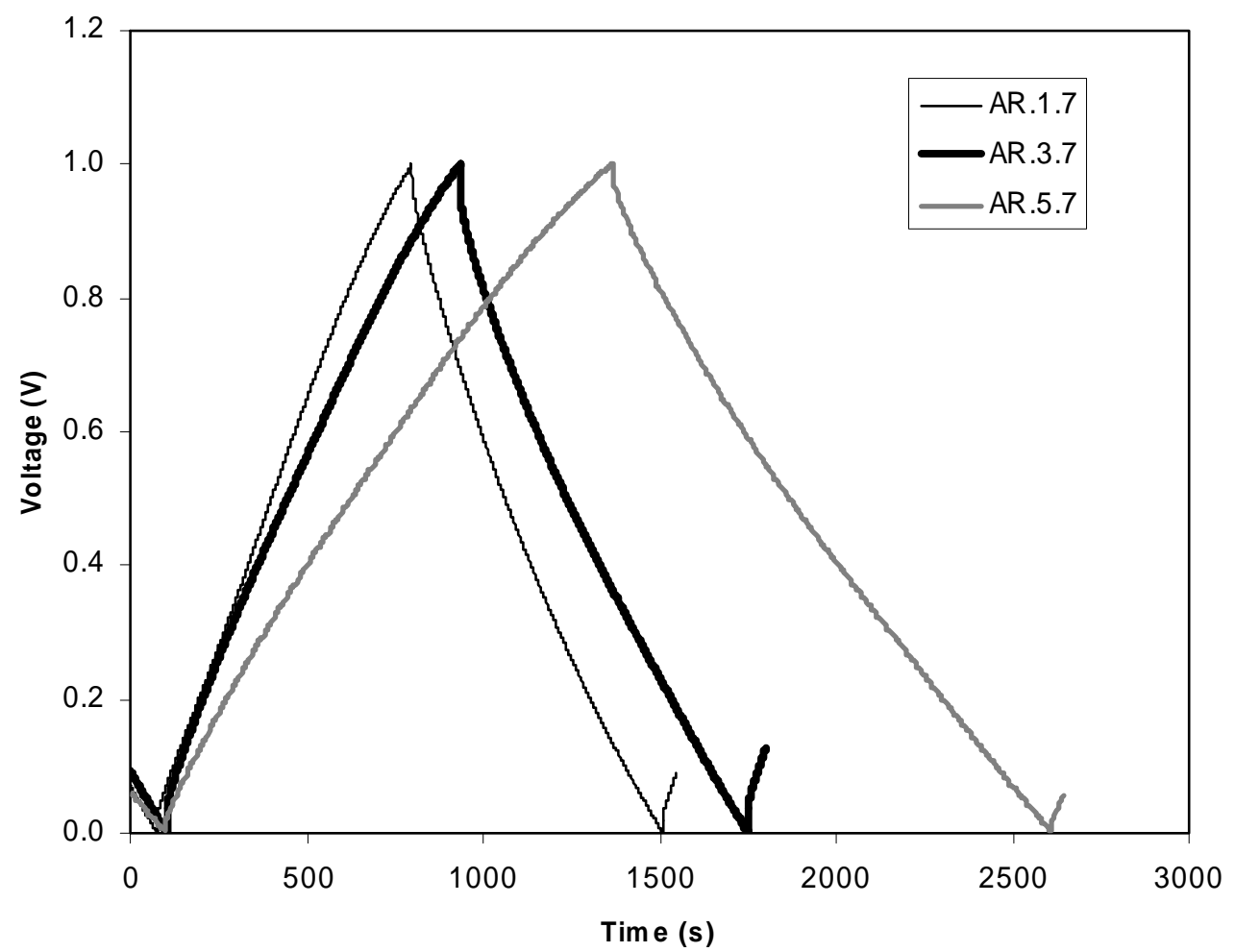

Figure 2 
a)

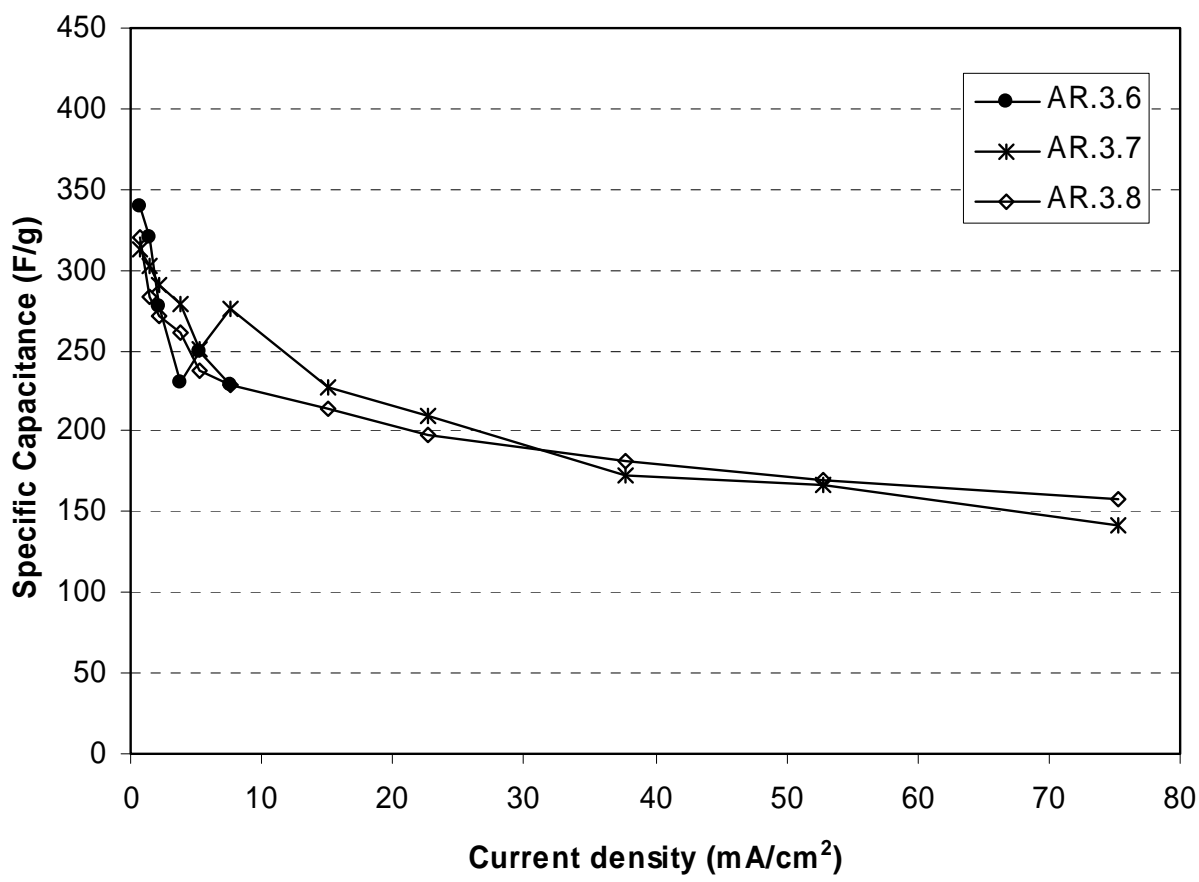

b)

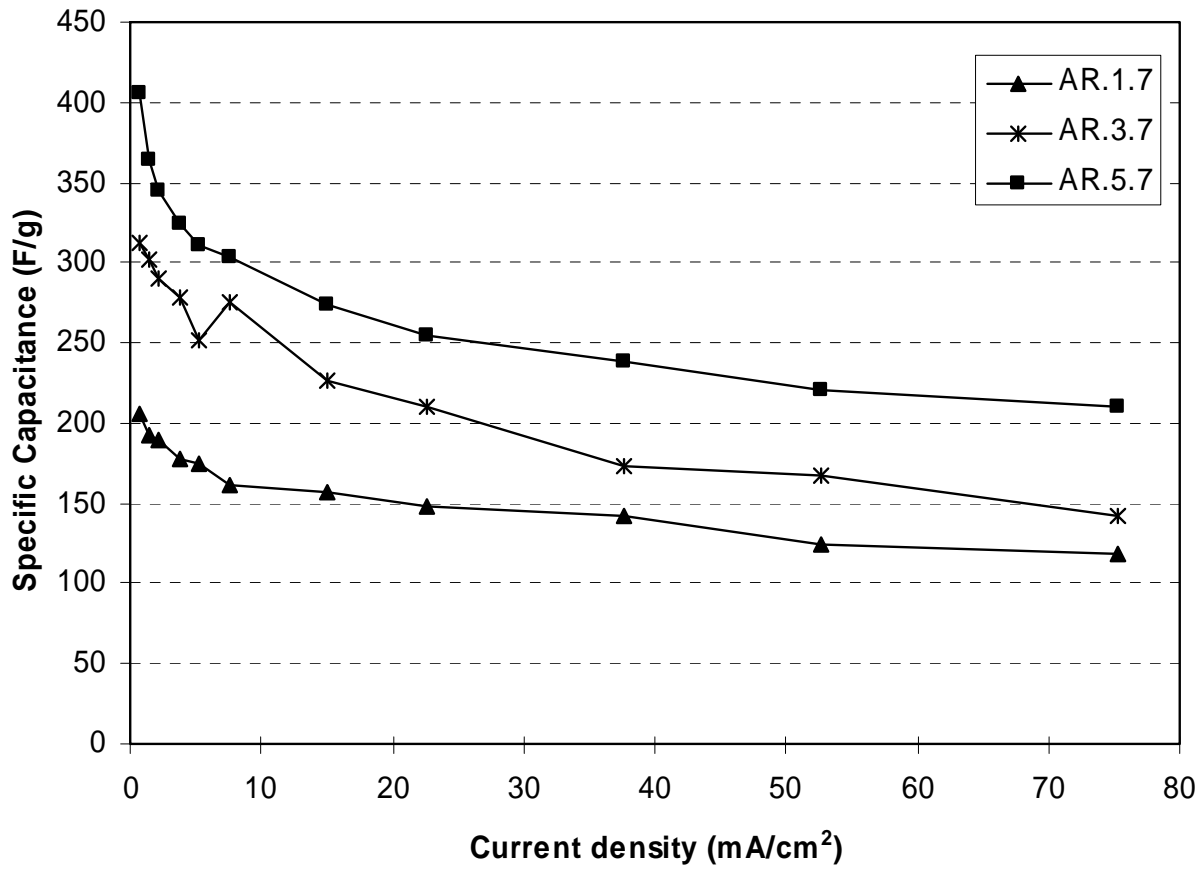

Figure 3 